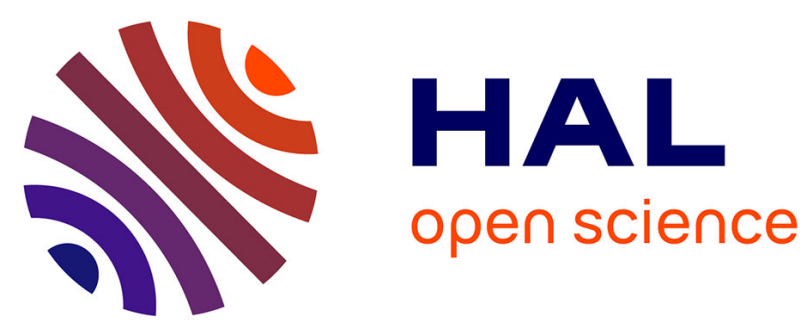

\title{
Covalently functionalized carbon nanotubes as stable cathode materials of lithium/organic batteries
}

\author{
Gaëlle Charrier, Antoine Desrues, Céline Barchasz, Jocelyne Leroy, Renaud
} Cornut, Bruno Jousselme, Stéphane Campidelli

\section{- To cite this version:}

Gaëlle Charrier, Antoine Desrues, Céline Barchasz, Jocelyne Leroy, Renaud Cornut, et al.. Covalently functionalized carbon nanotubes as stable cathode materials of lithium/organic batteries. Journal of Materials Chemistry A, 2016, 4, pp.15036 - 15040. 10.1039/C6TA05417J . cea-01377018

\section{HAL Id: cea-01377018 https://hal-cea.archives-ouvertes.fr/cea-01377018}

Submitted on 6 Oct 2016

HAL is a multi-disciplinary open access archive for the deposit and dissemination of scientific research documents, whether they are published or not. The documents may come from teaching and research institutions in France or abroad, or from public or private research centers.
L'archive ouverte pluridisciplinaire HAL, est destinée au dépôt et à la diffusion de documents scientifiques de niveau recherche, publiés ou non, émanant des établissements d'enseignement et de recherche français ou étrangers, des laboratoires publics ou privés. 


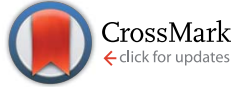

Cite this: J. Mater. Chem. A, 2016, 4, 15036

\section{Received 28th June 2016}

Accepted 31st August 2016

DOI: 10.1039/c6ta05417j

www.rsc.org/MaterialsA

\title{
Covalently functionalized carbon nanotubes as stable cathode materials of lithium/organic batteries $\dagger$
}

\author{
G. Charrier, ${ }^{a}$ A. Desrues, ${ }^{a}$ C. Barchasz, ${ }^{\star b}$ J. Leroy, ${ }^{a}$ R. Cornut, ${ }^{a}$ B. Jousselme ${ }^{a}$ \\ and S. Campidelli*a
}

\begin{abstract}
Lithium batteries are among the most promising systems for electrochemical energy storage. However, their capacity and cost-efficiency have to be improved for further applications, for instance in electric vehicles. In this context, lithium/organic batteries offer an interesting alternative to the classical Li-ion systems. Indeed, organic materials offer a high electrochemical activity depending on their functional groups and can be cost-effective if their synthesis is simple and well-controlled. The major problem of the lithium/organic systems developed so far is the progressive dissolution of the active molecules in the electrolyte upon cycling, leading to poor capacity retention. In this work, new positive electrode materials avoiding the dissolution of the active material in the electrolyte upon cycling are developed, by grafting anthraquinone diazonium salts to carbon nanotubes. Carbon nanotubes are used both to bring electronic conductivity to the positive electrode and to serve as a support for covalent immobilization of the active material. The resulting systems remain very stable over prolonged cycling $(80 \%$ of the initial capacity retained after 500 cycles) and present a promising specific capacity in the range of $100 \mathrm{~mA} \mathrm{~h}_{\text {gelectrode }}{ }^{-1}$.
\end{abstract}

\section{Introduction}

Li-ion batteries are among the most widespread electrochemical energy storage systems. Many portable electronic devices are equipped with these types of batteries, because of their attractive properties: relatively high volumetric energy densities, high operating voltage, good cyclability and low self-discharge. ${ }^{1-4}$ The principle underlying the operation of Li-ion batteries is based on the insertion/deintercalation of $\mathrm{Li}^{+}$into host materials at the anode and cathode. Their energy density is mainly restricted by the specific capacities of these intercalation materials. Today, the performances of Li-ion batteries seem to have reached intrinsic limits (about $250 \mathrm{~W} \mathrm{~h} \mathrm{~kg}{ }^{-1}$ ), ${ }^{3,5-8}$ while costs are still high. As a consequence, research efforts looking for new solutions with higher storage capacity, lower cost, and targeting electric vehicle requirements are ongoing. Li/organic batteries have recently attracted much attention due to the high theoretical specific capacity of organic materials, their low molecular weight, potential low cost and recyclability. ${ }^{9-12}$

${ }^{a}$ LICSEN, NIMBE, CEA, CNRS, Université Paris-Saclay, CEA Saclay, 91191 Gif-sur-Yvette Cedex, France. E-mail: stephane.campidelli@cea.fr

${ }^{b}$ CEA Grenoble, LITEN/DEHT/SCGE, Laboratoire des Générateurs Innovants (LGI), 17, rue des Martyrs, 38054 Grenoble Cedex 9, France.E-mail: celine.barchasz@cea.fr

† Electronic supplementary information (ESI) available: IR spectra of the 2-aminoanthraquinone and the diazo-anthraquinone; Raman and absorption spectra of purified and functionalized MWNTs; charge/discharge profiles of MWNTs mixed with anthraquinone. See DOI: 10.1039/c6ta05417j
At the end of the 90s, research studies on Li/organic batteries started to emerge. Several studies have been devoted to the study of conducting polymers (polyacetylene, polyaniline...) used as positive electrode materials..$^{\mathbf{1 0 1 3}-18}$ Recently, quinones have been identified as attractive materials as they present a characteristic two-electron transfer process accompanied by the capture of two Li ions. ${ }^{19-25}$ They can be integrated as positive electrode materials with good electrochemical reversibility and high storage capacities (theoretical values up to $450-500 \mathrm{~mA} \mathrm{~h} \mathrm{~g}_{\text {quinone }}{ }^{-1}$ ). ${ }^{10}$ Specifically, interesting results were obtained recently with anthraquinone either in the monomeric or polymeric forms. ${ }^{26-33}$ Yet, several problems have to be solved before commercialization of such systems. First, quinone derivatives and organic molecules in general are poorly conducting. This problem can be partially solved, for instance by the addition of carbon black or metallic additives into the electrode composition in order to improve the conductivity of the electrodes. Besides, an important drawback of the Li-organic batteries arises from the significant solubility of the molecules in classical organic electrolytes of the batteries, ${ }^{27,34,35}$ leading to important losses of the active material from the cathode after few charge/discharge cycles. A crucial issue is then to find a way to limit the dissolution of the active material by, for example, anchoring it at the positive electrode and then preserving the system from self-discharge and capacity fading.

In this work, we report the covalent functionalization of multiwalled carbon nanotubes (MWNTs) with an anthraquinone derivative and test the resulting material as a positive electrode in 
Li-organic batteries. To this end, 2-aminoanthraquinone is transformed into the corresponding diazonium salt and grafted to the surface of the MWNTs via the chemical reduction of the diazonium function. ${ }^{36}$ For the last 15 years, carbon nanotubes have attracted tremendous attention in the domains of energy production and storage because of their chemical and electrical properties which allow the fabrication of highly conductive and high specific surface area electrodes. ${ }^{37-40}$ Carbon nanotubes have been regularly used in lithium batteries to enhance the electronic conductivity of the materials and to improve the cyclability of the devices. ${ }^{\mathbf{4 0 , 4 1}}$ Here carbon nanotubes are used as positive electrode materials in lithium organic batteries to ensure the electronic conductivity of the electrode and act as a support for the covalent immobilization of the active material. Charge/discharge tests are then realized on purified and MWNTs grafted with the anthraquinone and on MWNTs simply mixed with the anthraquinone, i.e. without covalent grafting. The results highlight the fundamental importance of the covalent grafting of the MWNTs. Indeed, the anthraquinone molecules remain anchored to the electrodes and the systems remain stable over prolonged cycling and present a promising specific capacity in the range of $110 \mathrm{~mA} \mathrm{~h} \mathrm{~g}_{\text {electrode }}{ }^{-1}$ (for a maximal capacity of $260 \mathrm{~mA} \mathrm{~h} \mathrm{~g}^{-1}$ for anthraquinone alone, i.e. without carbonaceous additives).

\section{Materials and methods}

\section{Characterization techniques}

IR spectra were recorded on a Bruker alpha FT-IR spectrometer. XPS: a Kratos Analytical Axis Ultra DLD using an $\mathrm{Al} \mathrm{K} \alpha$ source monochromatized at $1486.6 \mathrm{eV}$ was employed. A hemispherical analyzer working at a pass energy of $160 \mathrm{eV}$ was used for the global spectra, and the sole core levels were recorded at $20 \mathrm{eV}$. Raman spectra were recorded on a Horiba Jobin-Yvon LabRAM ARAMIS with excitation at $532 \mathrm{~nm}$. UV-Vis-NIR absorption spectra were recorded on a Perkin Elmer Lambda 900 UV/VIS/NIR Spectrometer. Electrochemical measurements: preliminary tests were realized before cell assembly on a PGZ301 VoltaLab potentiostat using a classical three-electrode device with $\mathrm{Ag} / \mathrm{AgNO}_{3}$ as the reference electrode and glassy carbon as the counter electrode. The working electrode was composed either of purified MWNTs, functionalized MWNTs or glassy carbon. The electrolyte used was $\mathrm{LiClO}_{4}$ 0.1 M in acetonitrile. After coin cell assembly, the electrochemical tests were monitored with an Arbin ${ }^{\circledR}$ battery cycler (at 5 or $50 \mathrm{~mA} \mathrm{~g}_{\text {electrode }}{ }^{-1}$ between 1.5 and $3.5 \mathrm{~V} v$ s. $\mathrm{Li}^{+} / \mathrm{Li}$ ).

\section{Purification of carbon nanotubes}

Commercial grade multi-walled carbon nanotubes (NC3100 ${ }^{\mathrm{TM}}$ ) were purchased from Nanocyl. They were first purified by an oxidative treatment as follows: $:^{42}$ MWNTs (100 mg) were dispersed into $35 \%$ nitric acid $(300 \mathrm{~mL})$ by sonication for 30 minutes. The mixture was refluxed for 8 hours at $110{ }^{\circ} \mathrm{C}$. The nanotubes were then vacuum filtered through a $0.45 \mu \mathrm{m}$ PTFE membrane and washed with deionized water. They were redispersed in $\mathrm{NaOH} 2 \mathrm{M}$ by sonication for another 30 minutes before being vacuum filtered, washed with deionized water, with $\mathrm{HCl} 1 \mathrm{M}$, then water again and finally rinsed with acetone and diethyl ether.

\section{Synthesis of the diazo-anthraquinone $1^{43,44}$}

2-Aminoanthraquinone ( $1 \mathrm{~g}, 4.5 \mathrm{mmol}$ ) was reacted for 1 hour with one equivalent of $\mathrm{NOBF}_{4}(0.52 \mathrm{~g}, 4.5 \mathrm{mmol})$ in dry dichloromethane at $0{ }^{\circ} \mathrm{C}$. The solvent was vacuum removed and the product was dried under vacuum. The crude diazonium salt was stored at $-20{ }^{\circ} \mathrm{C}$ and used as it is.

\section{Functionalization of the nanotubes 2}

Purified MWNTs (10 mg) were dispersed in $N$-methylpyrrolidone by sonication for 30 minutes. The diazonium salt (275 mg, 1 equivalent per carbon) and a spatula tip of iron powder were then added. The solution was stirred for 12 hours at room temperature. The nanotubes were then vacuum filtered through a $0.45 \mu \mathrm{m}$ PTFE membrane and washed with $\mathrm{HCl} 1 \mathrm{M}$ and with deionized water. This functionalization procedure was repeated twice. Self-standing electrodes were obtained after filtration (16 $\mathrm{mm}$ diameter, $2 \mathrm{mg}$ ) and were integrated as positive electrodes in coin cells.

\section{Electrode cell assembly}

The coin cells were assembled in an argon-filled glove-box using CR2032 casing. $^{45}$ Lithium metal foil was used as a negative electrode and Celgard $2400 \AA$ as a separator. Either purified or functionalized nanotubes were used as self-standing positive electrode materials. A non-woven Viledon ${ }^{\circledR}$ separator (polyolefinbased) layer was also added between the positive electrode and the Celgard $®$ layer as an electrolyte reservoir. $150 \mu \mathrm{L}$ of electrolyte were added into the coin cells before sealing. The electrolyte was composed of lithium bis(trifluoromethanesulfonyl)imide (LiTFSI, 99.95\%, Aldrich) $1 \mathrm{M}$ dissolved in 50/50 tetraethylene glycol dimethyl ether (TEGDME, stored on molecular sieves, 99\%, Aldrich)/1,3-dioxolane (DIOX, anhydrous, 99.8\%, Aldrich). The measurements were reproduced on 5 cells fabricated with purified or functionalized MWNTs.

\section{Results and discussion, experimental}

The synthesis of the diazonium salt corresponding to the 2-aminoanthraquinone and the functionalization of MWNTs are shown in Scheme 1 . The diazonium derivative $\mathbf{1}$ was characterized by IR spectroscopy. A signal around $2300 \mathrm{~cm}^{-1}$ corresponding to the $" \mathrm{~N} \equiv \mathrm{N}^{+}$" function appears after the reaction, indicating the formation of the diazonium salt (see Fig. S1†).

Anthraquinone diazonium salts were then mixed with MWNTs in the presence of iron powder acting as a reducing agent to decompose the diazonium into the radical of anthraquinone that can react on the nanotube surfaces. ${ }^{36}$ Qualitative and quantitative analyses were performed before and after the functionalization step by means of XPS. Fig. 1a and $c$ show the surveys obtained respectively for purified and functionalized MWNTs. The total carbon and oxygen amounts were obtained by dividing the relevant peak integrated areas of well-defined C1s and O1s core level spectra by the appropriate bulk sensitivity factors. For purified MWNTs, the quantity of oxygen is about $5 \%$, due to the formation of oxidized surface 


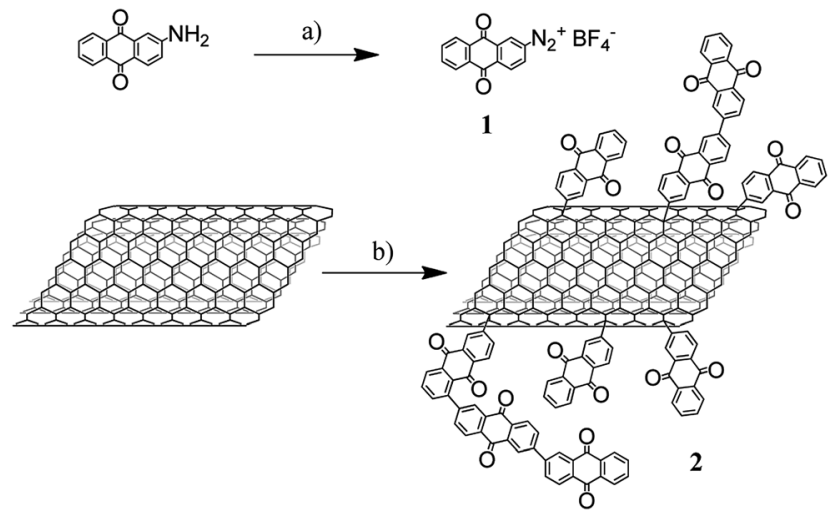

Scheme 1 Synthesis of the diazonium salt of the 2-aminoanthraquinone 1 and of the MWNT functionalized with anthraquinone 2; (a) $\mathrm{NOBF}_{4}, \mathrm{CH}_{2} \mathrm{Cl}_{2}, \mathrm{O}^{\circ} \mathrm{C}, 1 \mathrm{~h}$, quantitative; (b) 1, Fe powder, NMP, rt, $12 \mathrm{~h}$.
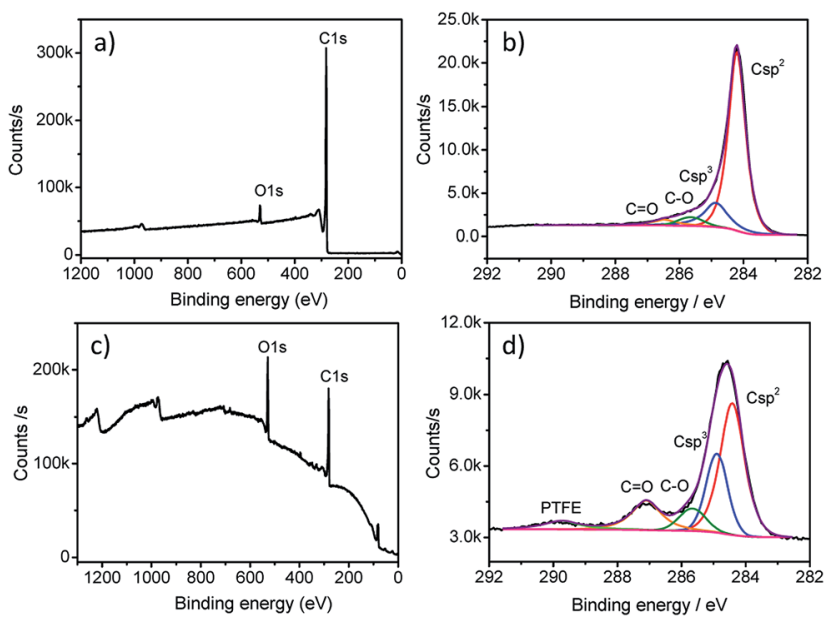

Fig. 1 XPS surveys of the purified (a) and functionalized MWNTs 2 (c); decomposition of the C1s peaks for purified (b) and functionalized MWNTs 2 (d); the peak at $290 \mathrm{eV}$ comes from the PTFE filtration membrane.

terminations such as " $\mathrm{C}=\mathrm{O}$ " or " $\mathrm{COOH}$ " after the purification process in nitric acid.

Fig. 1b and d show the decompositions of the C1s energy level signals for the purified MWNTs and functionalized MWNTs 2. Five Gaussian-Lorentzian curves were attributed to the various carbon atoms $\left(\mathrm{Csp}^{2}, \mathrm{Csp}^{3}, \mathrm{C}-\mathrm{O}\right.$ and $\left.\mathrm{C}=\mathrm{O}\right)$ present at the surface of the samples. ${ }^{42,46}$ After the grafting reaction, an important increase (up to 13\%) of the quantity of oxygen in the functionalized nanotube materials was observed and was attributed to the presence of anthraquinone molecules. SEM images were recorded for purified and grafted MWNTs, and they are presented in Fig. 2. After the two functionalization steps, the nanotubes are embedded in a thick coating of anthraquinone polymer, confirming the XPS results. The nanotube functionalization was also characterized by absorption and Raman spectroscopy (Fig. S2 $\dagger$ ). After functionalization with anthraquinone, the D-band, characteristic of the disorder in the $\mathrm{sp}^{2}$ structure of the nanotube, increased significantly.
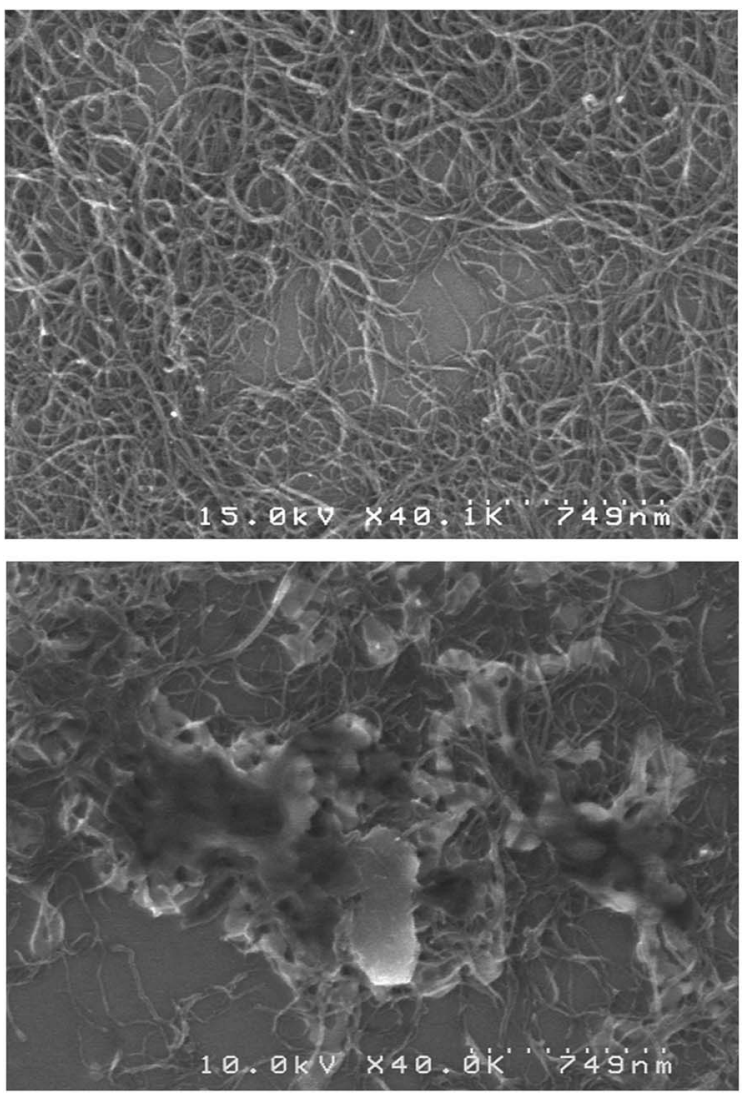

Fig. 2 SEM micrographs of purified MWNTs (top) and MWNT/ anthraquinone 2 (bottom).

However, no specific feature of the anthraquinone was observed. Absorption spectra show featureless decay typical of MWNTs.

The electrochemical activity of the purified and functionalized materials was tested using a classical three-electrode device with a silver reference electrode and glassy carbon as the counter electrode in acetonitrile using $\mathrm{LiClO}_{4}$ as the supporting electrolyte. ${ }^{47}$ First, the purified MWNT sample was used as a working electrode and cyclic voltammetry measurements were recorded (Fig. 3 black curve). No electrochemical activity was detected. In a second time, glassy carbon was used as a working electrode and the cyclic voltammetry of the anthraquinone was performed in solution (Fig. 3 blue curve). A reversible 2-electron reduction peak is observed at $-1.10 \mathrm{~V}$ with reoxidation at $-0.95 \mathrm{~V}$ vs. $\mathrm{Ag} / \mathrm{AgNO}_{3}$. Finally, MWNT/anthraquinone derivatives 2 were tested as a working electrode. The cyclic voltammogram exhibited similar reduction and oxidation peaks at -1.10 and $-0.70 \mathrm{~V} v s$. $\mathrm{Ag} / \mathrm{AgNO}_{3}$, respectively (Fig. 3 red curve). The peaks were attributed to the reduction and reoxidation of the quinone groups, confirming the presence of anthraquinone on the nanotube surfaces and the efficiency of the functionalization method.

Purified and functionalized MWNTs were integrated into coin cells and tested as positive electrode materials in Li/organic cells; charge/discharge profiles at $5 \mathrm{~mA}$ gelectrode $^{-1}$ are presented in Fig. $4 \mathrm{a}$ and $\mathrm{b}$ and $\mathrm{S} 3 . \dagger$ These results show a large increase of the discharge capacity for functionalized nanotubes 2 compared to 


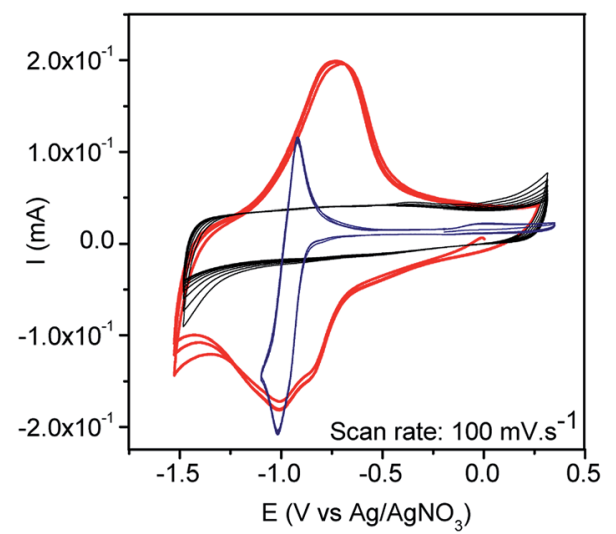

Fig. 3 Cyclic voltammetry for MWNTs (black line), glassy carbon with anthraquinone in solution (blue line), and MWNT/anthraquinone 2 (red line) in acetonitrile with $0.1 \mathrm{M} \mathrm{LiClO}_{4}$ as the supporting electrolyte.

bare nanotubes: a capacity of $110 \mathrm{~mA} \mathrm{~h}$ gelectrode $^{-1}$ is obtained with MWNT/anthraquinone 2, while purified MWNTs exhibit a capacity of around $5 \mathrm{~mA} \mathrm{~h} \mathrm{~g}_{\text {electrode }}{ }^{-1}$. For the MWNT-anthraquinone 2 positive electrode materials, a gravimetric energy density close to $240 \mathrm{~W} \mathrm{~h} \mathrm{~kg}_{\text {electrode }}{ }^{-1}$ can be extrapolated from the average potential and the specific capacity which is competitive with other $\mathrm{Li}$ /Organic cathode materials. ${ }^{10}$ Remarkably, the functionalized MWNTs 2 show an excellent stability as $98 \%$ of the initial capacity is retained after 50 cycles (Fig. 4c). Prolonged cycling performed at $50 \mathrm{~mA} \mathrm{~g} \mathrm{~g}_{\text {electrode }}{ }^{-1}$ showed that $80 \%$ of the
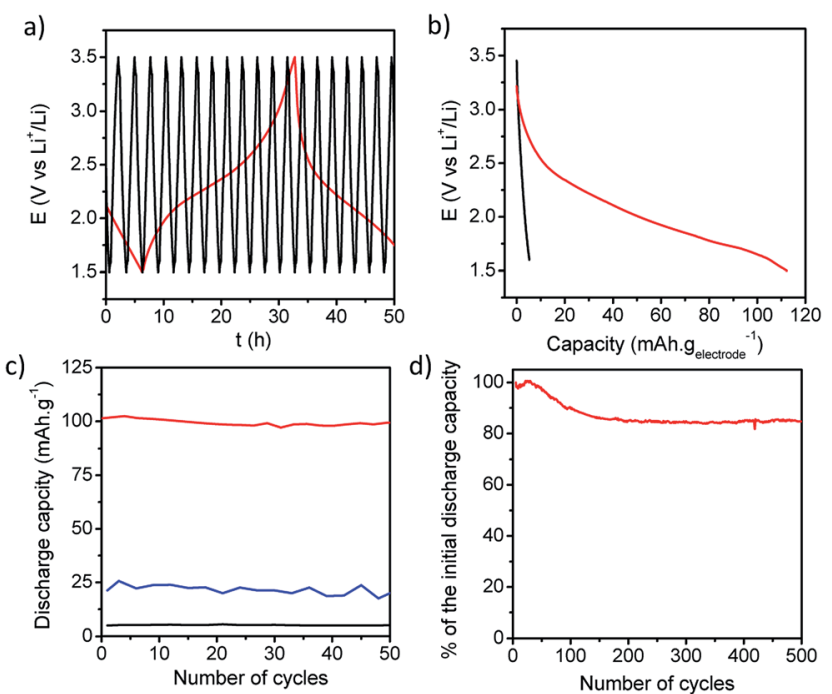

Fig. 4 (a) Charge/discharge profiles as a function of time for purified MWNTs (black) and MWNT/anthraquinone 2 (red) used as a positive electrode material in a Li/organic accumulator (2 mg samples, $5 \mathrm{~mA}$ gelectrode $^{-1}$ applied). (b) Discharge curves for purified MWNTs (black) and MWNT/anthraquinone 2 (red) as a function of the capacity. (c) Capacity retention of samples with purified MWNTs (black), MWNTs mixed with the anthraquinone molecule (blue) and MWNT/anthraquinone 2 (red) used as a positive electrode material. (d) Capacity retention over 500 cycles of a sample of MWNT/anthraquinone 2 used as a positive electrode material (50 $\mathrm{mA} \mathrm{gelectrode}^{-1}$ applied). initial capacity is retained after 500 cycles (Fig. 4d), with very limited evolution after the $100^{\text {th }}$ cycle.

To highlight the crucial role of the covalent linkage between the nanotubes and the active molecules, MWNTs were simply mixed with anthraquinone and tested in coin cells. A solution of anthraquinone was drop-cast on MWNT electrodes; the resulting mixture contained $50 \mathrm{wt} \%$ of anthraquinone which would give a maximal capacity of $130 \mathrm{~mA} \mathrm{~h}$ gelectrode $^{-1}$. After integration as a positive electrode material in a coin cell, discharge/ charge tests were realized (see Fig. $4 \mathrm{c}$ and $\mathrm{S} 4 \dagger$ ). Specific capacities of $c a .25 \mathrm{~mA} \mathrm{~h} \mathrm{~g}_{\text {electrode }}{ }^{-1}$ were obtained. This value is higher than the value obtained for the purified carbon nanotubes $\left(5 \mathrm{~mA} \mathrm{~h}\right.$ gelectrode $\left.^{-1}\right)$. Surprisingly, we did not observe a progressive loss of the capacity from 130 to $25 \mathrm{~mA} \mathrm{~h} \mathrm{~g}_{\text {electrode }}{ }^{-1}$ during the first cycles. We believe that the anthraquinone dissolves rapidly in the electrolyte and reacts with the lithium metal electrode, between coin cell fabrication and its electrochemical characterization. This proves that the covalent bonding of the active materials to the nanotubes is of primary importance both for the specific capacity and for the stability of the system. Post-mortem tests supported these conclusions: cells were disassembled after prolonged cycling and in the case of MWNT/anthraquinone covalently grafted 2 no brown coloration of the electrolyte was observed, indicating that the active material does not dissolve during cycling. Covalent bonding of the electroactive molecule to the MWNTs thus solves the principal issues described in the literature for Li/organic systems. ${ }^{10,34}$

In order to improve the storage capacity of these materials based on anthraquinone, we tried to reduce the ratio of carbon nanotubes/active molecules. Arc-discharge SWNTs (Carbon Solutions, Inc) and graphene obtained by exfoliation of graphite (NanoIntegris, PureSheet MONO ${ }^{\mathrm{TM}}$ ) were functionalized and tested in coin cells but both materials gave poor results due to the alteration of the conductive $\mathrm{sp}^{2}$ network during grafting and also because of the small particle sizes of exfoliated graphene. An alternative is to use double-walled carbon nanotubes; the proportion of carbon $v$ s. electroactive groups would thus be reduced while conserving the electronic properties of the systems thanks to the presence of non-grafted inner walls.

\section{Conclusions}

A new positive electrode material for Li/organic batteries has been developed by the covalent grafting of electroactive molecules (anthraquinone) to carbon nanotubes. This new material has been integrated into lithium batteries and discharge/charge tests were performed. Our system presents an excellent stability over prolonged cycling, as $98 \%$ of the specific capacity is retained after 50 cycles. This method provides a simple and efficient solution to the issue of the dissolution of the active material in the electrolyte, a well-known problematical phenomenon for Li/organic cells. The storage capacity (equal to $110 \mathrm{~mA} \mathrm{~h}$ gelectrode $^{-1}$ in the present work) can be improved by reducing the ratio between the carbonaceous material and the active functions, or by the use of electroactive molecules exhibiting higher theoretical capacities (e.g. naphthoquinone instead of anthraquinone). Optimization is 
in progress to obtain the thickest coating as possible, while preserving good charge and mass transport properties. The method developed in this work can be applied for other metals acting as negative electrode materials such as $\mathrm{Na}$ and $\mathrm{Zn}$.

\section{Acknowledgements}

The authors acknowledge the "Programme Transversal Nanosciences" and the NTE program from CEA (Project Naturalis) for financial support. The authors would also like to graciously thank Dr Fannie Alloin and Prof. Jean-Claude Leprêtre (LEPMI) for fruitful discussion and collaboration.

\section{Notes and references}

1 M. Armand and J.-M. Tarascon, Nature, 2008, 451, 652.

2 F. Cheng, J. Liang, Z. Tao and J. Chen, Adv. Mater., 2011, 23, 1695.

3 V. Etacheri, R. Marom, R. Elazari, G. Salitra and D. Aurbach, Energy Environ. Sci., 2011, 4, 3243.

4 J.-M. Tarascon and M. Armand, Nature, 2001, 414, 359.

5 J. Chen and F. Cheng, Acc. Chem. Res., 2009, 42, 713.

6 A. K. Padhi, K. S. Nanjundaswamy and J. B. Goodenough, J. Electrochem. Soc., 1997, 144, 1188.

7 N. Ravet, Y. Chouinard, J. F. Magnan, S. Besner, M. Gauthier and M. Armand, J. Power Sources, 2001, 97-98, 503.

8 M. S. Whittingham, Chem. Rev., 2004, 104, 4271.

9 J. Hong, M. Lee, B. Lee, D. H. Seo, C. B. Park and K. Kang, Nat. Commun., 2014, 5, 5335.

10 Y. Liang, Z. Tao and J. Chen, Adv. Energy Mater., 2012, 2, 742.

11 Z. Song, Y. Qian, M. L. Gordin, D. Tang, T. Xu, M. Otani, H. Zhan, H. Zhou and D. Wang, Angew. Chem., Int. Ed., 2015, 54, 13947.

12 Z. Song, Y. Qian, M. Otani and H. Zhou, Adv. Energy Mater., 2016, 6, 1501780 .

13 L. Bugnon, C. J. H. Morton, P. Novak, J. Vetter and P. Nesvadba, Chem. Mater., 2007, 19, 2910.

14 K. Nakahara, S. Iwasa, M. Satoh, Y. Morioka, J. Iriyama, M. Suguro and E. Hasegawa, Chem. Phys. Lett., 2002, 359, 351.

15 H. Nishide, S. Iwasa, Y.-J. Pu, T. Suga, K. Nakahara and M. Satoh, Electrochim. Acta, 2004, 50, 827.

16 P. Novák, K. Müller, K. S. V. Santhnam and O. Haas, Chem. Rev., 1997, 97, 207.

17 K. Oyaizu and H. Nishide, Adv. Mater., 2009, 21, 2339.

18 P. Poizot and F. Dolhem, Energy Environ. Sci., 2011, 4, 2003.

19 D. Häringer, P. Novák, O. Haas, B. Piro and M.-C. Pham, J. Electrochem. Soc., 1999, 146, 2393.

20 T. Le Gall, K. H. Teiman, M. C. Grossel and J. R. Owen, J. Power Sources, 2003, 119-121, 316.

21 K. Liu, J. Zheng, G. Zhong and Y. Yang, J. Mater. Chem., 2011, 21, 4125.
22 M. Pasquali, G. Pistoia, T. Boschi and P. Tagliatesta, Solid State Ionics, 1987, 23, 261.

23 Z. Zhu, M. Hong, D. Guo, J. Shi, Z. Tao and J. Chen, J. Am. Chem. Soc., 2014, 136, 16461.

24 B. Häupler, A. Wild and U. S. Schubert, Adv. Energy Mater., 2015, 5, 1402034.

25 Y. Liang, P. Zhang, S. Yang, Z. Tao and J. Chen, Adv. Energy Mater., 2013, 3, 600.

26 P. Bu, S. Liu, Y. Lu, S. Zhuang, H. Wang and F. Tu, Int. J. Electrochem. Sci., 2012, 7, 4617.

27 A. Iordache, V. Maurel, J.-M. Mouesca, J. Pécaud, L. Dubois and T. Gutel, J. Power Sources, 2014, 267, 553.

28 Z. Song, Y. Qian, X. Liu, T. Zhang, Y. Zhu, H. Yu, M. Otani and H. Zhou, Energy Environ. Sci., 2014, 7, 4077.

29 Z. Song, H. Zhan and Y. Zhou, Chem. Commun., 2009, 448.

30 W. Wang, W. Xu, L. Cosimbescu, D. Choi, L. Li and Z. Yang, Chem. Commun., 2012, 48, 6669.

31 M. Yao, S.-I. Yamazaki, H. Senoh, T. Sakai and T. Kiyobayashi, Mater. Sci. Eng., B, 2012, 177, 483.

32 R.-H. Zeng, X.-P. Li, Y.-C. Qiu, W.-S. Li, J. Yi, D.-S. Lu, C.-L. Tan and M.-Q. Xu, Electrochem. Commun., 2010, 12, 1253.

33 L. Zhao, W.-K. Wang, A.-B. Wang, Z.-B. Yu, S. Chen and Y.-S. Yang, J. Electrochem. Soc., 2011, 158, A991.

34 Z. Song and H. Zhou, Energy Environ. Sci., 2013, 6, 2280.

35 L. J. Xue, J. X. Li, S. Q. Hu, M. X. Zhang, Y. H. Zhou and C. M. Zhan, Electrochem. Commun., 2003, 5, 903.

36 V. Mévellec, S. Roussel, L. Tessier, J. Chancolon, M. MayneL'Hermite, G. Deniau, P. Viel and S. Palacin, Chem. Mater., 2007, 19, 6323.

37 L. J. Brennan, M. T. Byrne, M. Bari and Y. Gun'ko, Adv. Energy Mater., 2011, 1, 472.

38 R. D. Costa, F. Lodermeyer, R. Casillas and D. M. Guldi, Energy Environ. Sci., 2014, 7, 1281.

39 M. Zhou, H.-L. Wang and S. Guo, Chem. Soc. Rev., 2016, 45, 1273.

40 C. Gong, Z. Xue, S. Wen, Y. Ye and X. Xie, J. Power Sources, 2016, 318, 93.

41 Y. Fu, Y.-S. Su and A. Manthiram, Angew. Chem., Int. Ed., 2013, 52, 6930.

42 I. Hijazi, T. Bourgeteau, R. Cornut, A. Morozan, A. Filoramo, J. Leroy, V. Derycke, B. Jousselme and S. Campidelli, J. Am. Chem. Soc., 2014, 136, 6348.

43 S. Ernst, L. Aldous and R. G. Compton, Chem. Phys. Lett., 2011, 511, 461.

44 D. J. Milner, Synth. Commun., 1992, 22, 73.

45 C. Barchasz, J.-C. Leprêtre, S. Patoux and F. Alloin, Electrochim. Acta, 2013, 89, 737.

46 A. Jung, R. Graupner, L. Ley and A. Hirsch, Phys. Status Solidi $B, 2006,243,3217$.

47 B. Piro, E. A. Bazzaoui, M.-C. Pham, P. Novak and O. Haas, Electrochim. Acta, 1999, 44, 1953. 